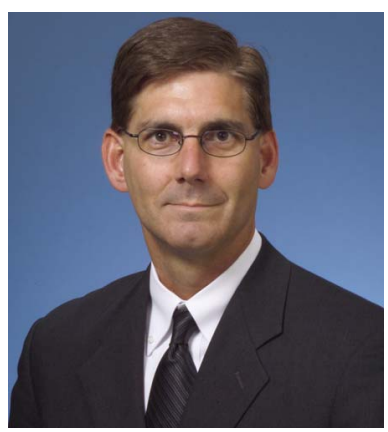

\title{
How Do You Write a Great Abstract and Why Is It Important?
}

Why would you ever want to read a Driggers editorial and, in particular, this editorial? Is it the free beer that I might buy for you if you do read it and want to sit down and discuss it with me? No, it is because if you do, there is a good chance you will become a better author in that you will understand what makes up a great abstract. There. Did I sell you on reading the whole editorial? Good, because that is one of the important aspects of a great abstract. It is a hook to convince a reader to invest the time to acquire and read your entire paper.

At one of the SPIE meetings this last year, I ran into Bill Rhodes, who is the editor of SPIE Reviews. He is a longtime friend, now after many years at George Tech a professor at Florida Atlantic University, who has been involved in optics and photonics publishing for many years. He told me that he thought the quality of abstracts has diminished over the past years and that not many people really knew how to write a good abstract. He asked me what a good abstract was, and for the life of me, I could not answer Bill with a concise summary (to be honest, I was a little tongue-tied, and what I actually spit out was not coherent at all).

I did a quick search on how to write a good abstract and I ran across Phil Koopman's webpage at http:// www.ece.cmu.edu/ koopman/essays/abstract.html. Phil is a professor at Carnegie Mellon University and has put together a superb summary for his graduate students. In fact, this is the website that SPIE references for writing abstracts. Phil states that the abstract is a way of "selling" your paper (convincing readers to read the whole paper) and that it is an executive summary of a journal publication. According to Phil, a good abstract should have five "sections" that are a sentence or a few sentences each (and I am paraphrasing to shorten the description):

- Motivation: Why do we care? Includes importance, impact, and difficulty of the research area.

- Problem Statement: What are you trying to solve? Includes scope (general, specific).

- Approach: How did you solve, or make progress on, the problem (simulation, prototype, analysis)? Includes approach, extent, and variables.

- Results: What is the answer? Includes faster, cheaper, etc. Use numbers and not vague phrases like "significant."

- Conclusions: What are the implications of your answer? Describe how your results will be used in a general or specific way.

I encourage you to read Phil's short paper at the above link, because it will provide you with a better means to write a great abstract. He states that an efficient abstract is hard work, but it will pay off because more people will read your papers. I would like to add that the more people you can get to read your paper, the more people are likely to cite your papers (and increase your citation rate). Why are citations important? Because many universities and research institutions evaluate their scientists and engineers with metrics that include citation rates (such as the h-index).

One last thing worth mentioning comes from Eric Pepper, the director of publications at SPIE. Today, when someone reads your abstract it is very likely to be online, and you are really trying to get them to click through to read the full text if they have access, seek out another source such as Google or the author's website for the paper, or purchase the paper (online hopefully). This is much easier than the old trip to the library, but the hook is the same. That is, you want the reader to take the next step and read the paper.

Once long ago, I taught a course in electro-optics out of my first book. I knew I was going to update the book and to get the students to really read the book and give me constructive feedback, I offered $\$ 5$ for every error they could find. That semester I almost went broke. I think I lost \$100 and at the end of the semester, the students knew the material better than I did. I'm not suggesting that you attach \$5 to your abstract to get people to read your paper. Writing a great abstract is a much better approach.

Ronald G. Driggers Editor

P.S. Bill Rhodes has agreed to write a follow-on guest editorial next month on the changes in perception of what purpose an abstract should serve. 